Int. J. Electrochem. Sci., 15 (2020) 12203 - 12219

\title{
Preparation and Corrosion Resistance of ZIF-8-(5, 6- dimethylbenzimidazole)/LDHs Composite Film on Magnesium Alloy
}

\author{
Huimin Yang ${ }^{1,2}$, Xin Liu $^{1,2}$, Jihui Wang ${ }^{1,2, *}$ and Wenbin $\mathrm{Hu}^{2}$ \\ ${ }^{1}$ State Key Laboratory of Hydraulic Engineering Simulation and Safety, Tianjin University, Tianjin \\ 300072, P R China; \\ 2 Tianjin Key Laboratory of Composite and Functional Materials, School of Materials Science and \\ Engineering, Tianjin University, Tianjin 300072, P R China; \\ *E-mail: jhwang@tju.edu.cn
}

doi: $10.20964 / 2020.12 .73$

Received: 22 August 2020 / Accepted: 15 October 2020 / Published: 31 October 2020

\begin{abstract}
The following study is conducted to improve the corrosion resistance of magnesium alloy. First, $\mathrm{ZnAl}$ layered double hydroxide ( $\mathrm{ZnAl} \mathrm{LDH})$ film was prepared on AZ61 magnesium alloy by using hydrothermal method. Then, as-prepared $\mathrm{ZnAl} \mathrm{LDH}$ was put into 2-methylimidazole (2-mIm) solution to synthetize ZIF-8 film (ZIF-8/LDH). Finally, ZIF-8/LDH film synthesized ZIF-8-DMBIM film (ZIF8-DMBIM/LDHs) via a shell-ligand-exchange-reaction in the methanol solution containing 5, 6dimethylbenzimidazole (DMBIM). The surface morphology, structure, and composition of the composite film were observed and determined by scanning electronic microscopy, X-ray diffraction, Fourier transform infrared spectroscopy, and energy-dispersive X-ray spectroscopy. The wettability of composite film was measured by using a water contact angle meter, and the corrosion resistance of the composite film was estimated by the polarization curve and electrochemical impedance spectroscopy techniques. Results show that the prepared ZIF-8-DMBIM/LDH composite film has a dense hexagonal plate morphology with a two-layer structure and a thickness of $3.5 \mu \mathrm{m}$. Compared with ZnAl LDH and ZIF-8/LDH films, ZIF-8-DMBIM/LDH composite film has a high contact angle $\left(115.7^{\circ}\right)$, low corrosion current density, and high corrosion potential and polarization resistance due to its near-smooth surface, dense two-layer structure, and hydrophobic characters.
\end{abstract}

Keywords: Magnesium alloy; Corrosion resistance; Composite film; Metal organic framework; Layered double hydroxide; Hydrophobicity

\section{FULL TEXT}


(C) 2020 The Authors. Published by ESG (www.electrochemsci.org). This article is an open access article distributed under the terms and conditions of the Creative Commons Attribution license (http://creativecommons.org/licenses/by/4.0/). 